\title{
Artelogie
}

Recherche sur les arts, le patrimoine et la littérature de l'Amérique latine

$3 \mid 2012$

Image de la nation : art et nature au Chili

\section{La naturaleza en los escritos sobre cine chileno primitivo}

José M. Santa Cruz G.

(2) OpenEdition

Journals

Edición electrónica

URL: https://journals.openedition.org/artelogie/7148

DOI: $10.4000 /$ artelogie. 7148

ISSN: 2115-6395

Editor

Association ESCAL

Referencia electrónica

José M. Santa Cruz G., «La naturaleza en los escritos sobre cine chileno primitivo», Artelogie [En línea],

3 | 2012, Publicado el 12 septiembre 2012, consultado el 07 enero 2022. URL: http://

journals.openedition.org/artelogie/7148; DOI: https://doi.org/10.4000/artelogie.7148

Este documento fue generado automáticamente el 7 enero 2022.

Association ESCAL 


\title{
La naturaleza en los escritos sobre cine chileno primitivo
}

\author{
José M. Santa Cruz G.
}

\section{NOTA DEL EDITOR}

Este artículo es un producto residual del proyecto de investigación "Modelos de la crítica", dirigido por los investigadores Claudio Salinas y Hans Stange, del Instituto de Comunicación e Imagen-ICEI de la Universidad de Chile, y financiado por el Fondo Audiovisual del Consejo Nacional de la Cultura y las Artes, Gobierno de Chile, 2011.

1 Preguntarse por la naturaleza al interior del desarrollo del cine chileno es cuestionarse un motivo representacional que ha cruzado gran parte de su producción, que no puede circunscribirse a una época, momento o gesto sin con ello generar una censura de la propia fertilidad del problema. Sobre todo si tomamos en cuenta que el campo teórico cinematográfico local ha ausentado un estudio serio, sostenido y que se escape a lo meramente anecdótico sobre el tema o, más aún, cuando simplemente lo ha dejado en manos de reflexiones con tintes culturales, historiográficos o antropológicos. Así, dirigir la mirada hacia el problema de la naturaleza al interior del cine, nos devuelve un panorama altamente opaco o difuso, de una topografía incógnita, donde el propio gesto analítico es puesto bajo cuestión, en la imposibilidad de convocar un espacio de repetición en el cual reverberen las ideas y conceptos.

2 La casi nula bibliografía dentro de la teoría cinematográfica local sobre el tema, se presenta como un desafío a sortear a través de la visibilización de algunas huellas en artículos, ensayos o escritos. Un ejemplo de ello es la relación entre ciertos tópicos representacionales y la naturaleza que trabaja Felipe Maturana en su análisis de tres documentales recientes sobre los indígenas fueguinos. Éste pone de relieve como aún en la actualidad, lo indígena está tratado en su excepcionalidad exótica y donde la figura de la naturaleza es su catalizador estético. "[...] el tercer motivo en importancia de planos sea el Paisaje, símbolo de la armonía y equilibrio natural del indígena con su 
entorno y el cosmos (imágenes del Sol, la Luna, y las Estrellas son frecuentes en las tres obras analizadas)" (MATURANA, 2010: s/n pp.).

En una perspectiva más amplia, pero afín a la desarrollada por Maturana, se presenta un artículo de María Paz Peirano, en que expone las dicotomías entre las representaciones del sujeto popular y el sujeto indígena dentro de la cinematografía chilena a finales de los años noventa e inicios de la primera década del siglo XXI. Peirano establece que en el cine chileno existe una exclusión de lo indígena como parte de la sociedad, en pro de la construcción de una identidad popular nacional «blanqueada», es decir, donde el imaginario social representado no refiere al imaginario de quien desarrolla la representación. Éste imaginario sería desarrollado por cierta elite intelectual, que si bien tiene una simpatía discursiva por el sujeto popular e indígena, nunca se cuestiona su propio rol de construcción de estereotipos. Esta doble tensión resultante se expresará, según sus propias palabras, en "una doble identificación, que no deja de ser contradictoria, puesto que las características con que se suele asociar lo nacional (tradicional, comunitario, ritualista, festivo, religioso, rural) son muy cercanas a las características con que se dibuja la imagen de lo indígena (ancestral, comunitario, ritualista, religioso, festivo, rural, natural)" (PEIRANO, 2006: p. 64).

4 En este sentido, se vuelve relevante el matiz que la propia Peirano nos impulsa a reconocer, donde "el ethnoscape de lo indígena es el descampado, mientras que el paisaje asociado a lo popular es un poblado rural construido" (PEIRANO, 2006: p. 64). Es decir, lo indígena esta asociado a la naturaleza y su representación audiovisual se construye como un descampado que, por un lado, no tiene una intervención cultural, y por otro, debe generar la idea de pobreza. Las perspectivas de Peirano complejizan profundamente lo que algunos, como Bernardo Subercaseaux, identifican en la reactivación estética de una vertiente de « cuño nacionalista autoritario » durante la dictadura chilena (1973-1990) y que aún pervive en el imaginario colectivo chileno, donde "su eje fue una concepción telúrico-metafísica del ser chileno, según la cual éste es concebido como una esencia forjada en el entrecruzamiento del hombre con la naturaleza, esencia que estaría latente en todos los habitantes del territorio nacional. Desde esta concepción la cultura fue percibida como manifestación de una esencia invariable" (SUBERCASEAUX, 2006: s/n pp.). Explicado también por Isabel Jara:

[...] la interpelación política del paisaje local con el argumento histórico (como espacio de la añorada sociedad "prepolítica ", en tanto premoderna), con el argumento psicosocial (como formador y manifestación del temperamento chileno) y con el argumento geopolítico (ser componente del todo nacional). En segundo lugar, apuntó a la exhortación del paisaje tradicional como núcleo del orden social jerárquico y disciplinado que había originado la «chilenidad». Y tercero, reforzó los imperativos de la DSN [Doctrina de Seguridad Nacional] sobre el paisaje como proyección de un Estado vivo, enérgico y territorialmente insatisfecho. (JARA, 2011: p. 249) 


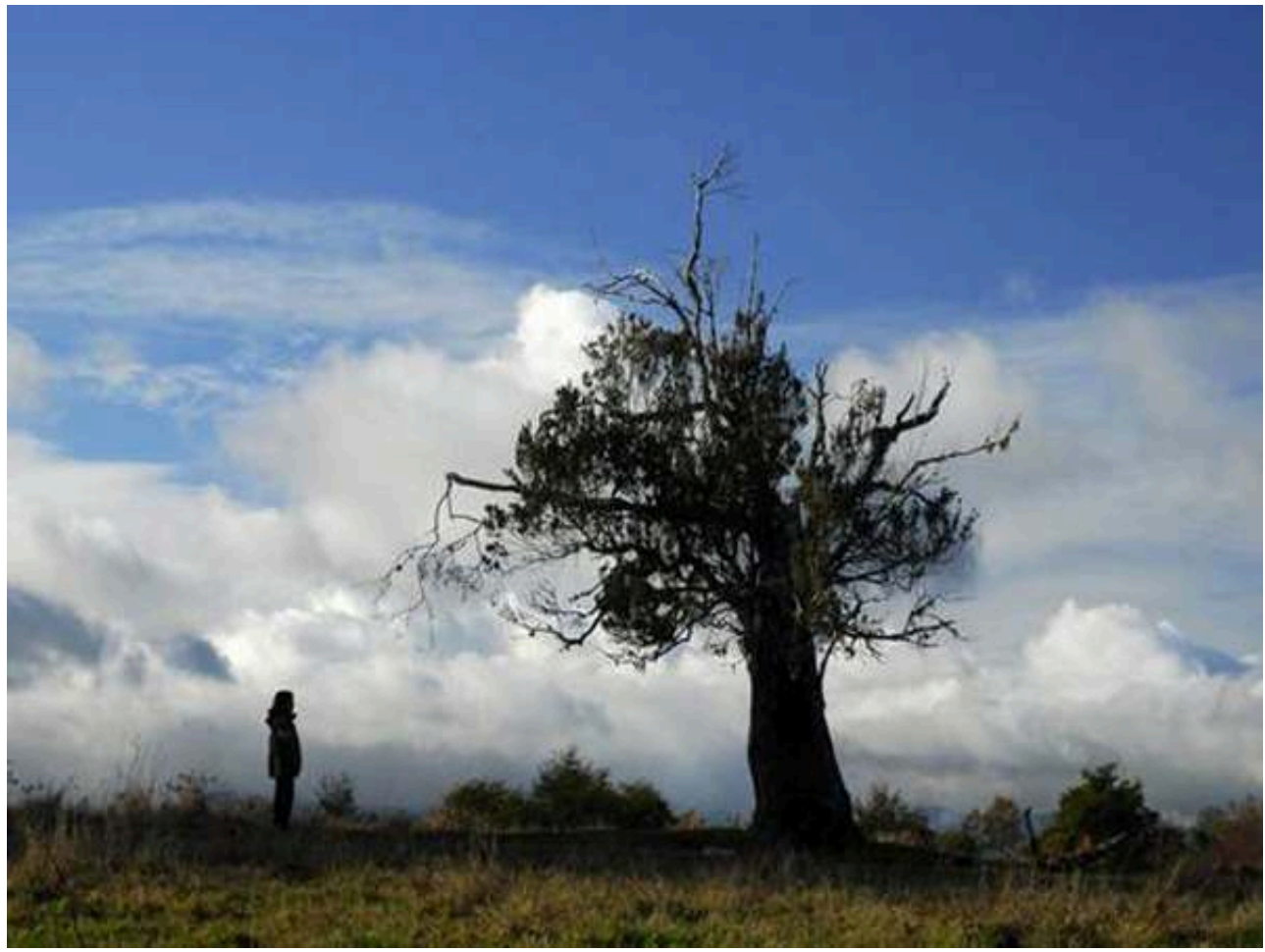

5 Fuera de un contexto académico, aparecen algunas cuantas críticas cinematográficas a propósito de dos filmes estrenados en el año 2008 (Alicia en el país de Esteban Larraín y El cielo, la tierra y la lluvia de José Luis Torres Leiva), que problematizan directamente el rol activo de la naturaleza en la construcción discursiva de dichos filmes. La primera, escrita por el documentalista Christián Ramírez, plantea que en ambos filmes la naturaleza "más que entrar en relación con los protagonistas, francamente los enfrenta; deja de ser un mero decorado y pasa a transformarse en una presencia, en una entidad que habita estos filmes como pocos personajes lo han hecho jamás en una película chilena" (RAMÍREZ, 2008: s/n pp.). Por su lado, Iván Pinto Veas planteará, a propósito del filme de Larraín, que en los "largos planos con bellas fotografías del desierto, la relación con el paisaje no logra salir del esteticismo" (PINTO, 2009: s/n pp.). Y, por su lado, Alberto Ramos, criticando el filme de Torres Leiva y de forma similar que Ramírez comprende que la naturaleza al interior del filme:

[...] rebasa lo meramente decorativo. Lo que a primera vista puede tomarse como un retrato de grupo en un marco de sobrecogedora grandeza: cuatro solitarios irredimibles cuyas vidas se entrecruzan sin otro resultado que no sea más soledad y extravío, deviene comprensión del paisaje como construcción totalizadora, en que los accesos de melancolía y el fantasma de la incomunicación aparecen como trazos inscritos en una estructura trascendente, reverberante. (RAMOS, 2008: s/n pp.)

6 Una dirección muy distinta es la que se encuentra en un artículo de Mario Godoy Quezada -el que podríamos denominar como el primer historiador del cine local ${ }^{1}$ quien hace un pequeño recorrido sobre el motivo del mar en la cinematografía chilena desde sus inicios hasta finales de los años cincuenta. Si bien reconoce unos pocos filmes que lo trabajan, como Un grito en el mar (1924), de Pedro Sienna, Cabo de Hornos (1956), de Tito Davison, o La caleta olvidada (1958), de Bruno Gebel, terminará por sancionar:

En un pueblo ineludiblemente oceánico como el chileno, es lógico que su creación artística, en todas sus manifestaciones, se enriquezca con los temas marinos. Por 
ello surge la esperanza que al ingresar nuestro cine, alguna vez, a una etapa madura, la enigmática belleza del Pacífico se proyecté en toda su grandiosidad en las pantallas chilenas. (GODOY QUEZADA, 1967: p.28)

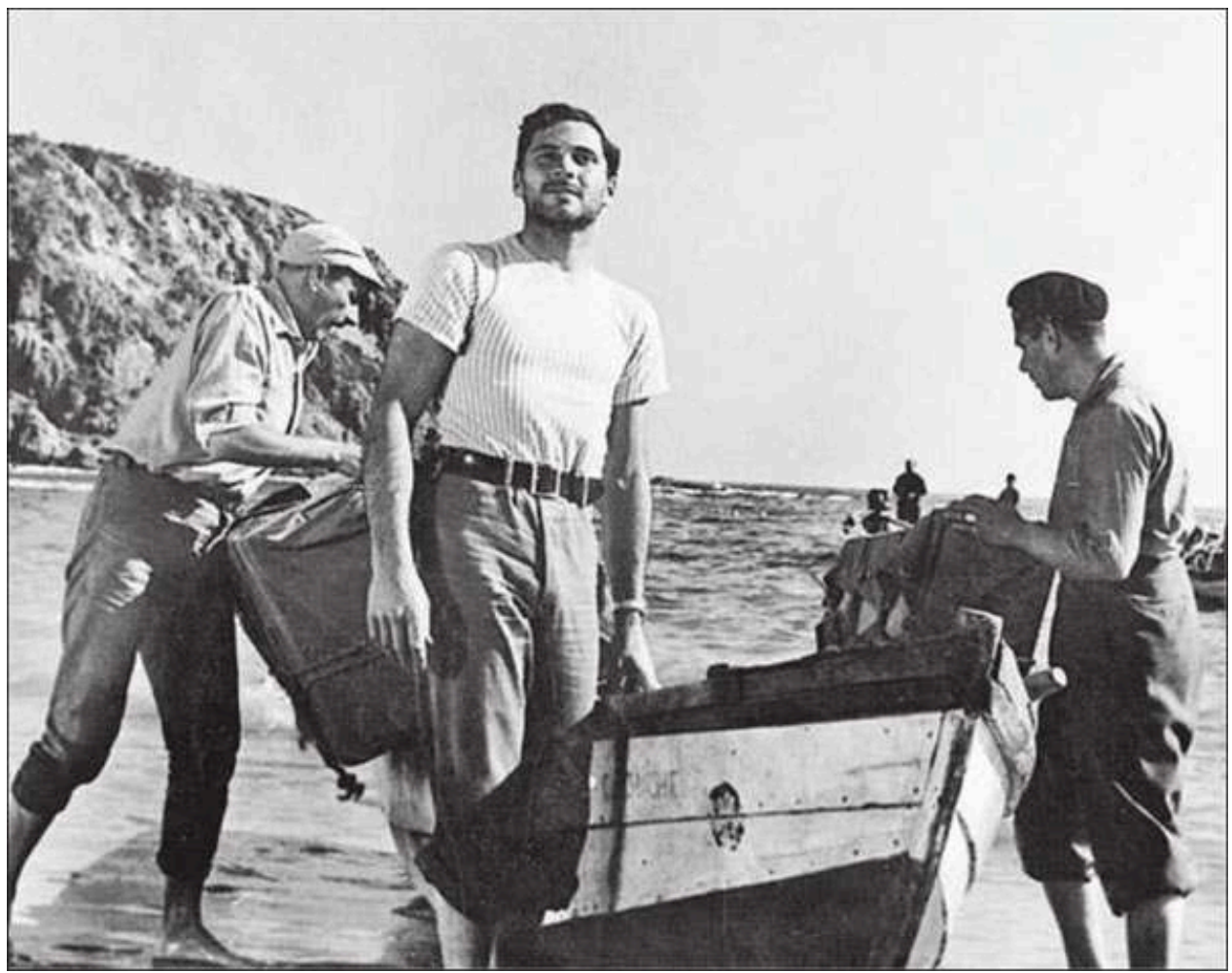

Enciclopedia del cine chileno, Cine Chile

7 Ahora bien, como es evidente en esta pequeña muestra -que podría haber sido cualquier otra- no hemos interrogado a los textos, sino simplemente hemos enunciado algunas de sus referencias al problema, ya que justamente éstos no logran visibilizar en su interior un problema teórico local, sino que lo enuncian y pasan rápidamente por él, lo marcan y se desmarcan. Esto puede responder a lo que Ramírez, mientras analiza los filmes de Torres Leiva y Larraín, citando al crítico de cine Juan Pablo Vilches, comprende como deficiencia del sustrato cultural chileno, ya que a diferencia de los cineastas europeos éstos "están asociados en forma previa e indisoluble a un rico sustrato cultural: su mirada está cruzada por cientos de años de evocaciones de la naturaleza realizada en el marco del arte europeo" (RAMÍREZ, 2008: s/n pp.).

Esta perspectiva se vuelve insuficiente en varios aspectos: el primero es su infertilidad crítica, es decir, no se puede dimensionar las operaciones paisajistas o las formas audiovisuales de la naturaleza en los cineastas locales, en la medida en que se carece de un sustrato anterior que le den un marco estético referencial y reflexivo. El segundo es su autonomización: no se despliega al cine en una reflexión mayor sobre el régimen representacional y del arte, que le posibilite por ejemplo, vincularse con el documental televisivo en programas como La tierra en que vivimos (TVN) o Al sur del mundo (Canal 13) -que sí tomaron la naturaleza como un motivo privilegiado en sus dispositivos audiovisuales-, o también con la artes visuales o la literatura. El tercero es dotar de un marco ideológico para una imagen cinematográfica-audiovisual carente de memoria y 
a-histórica, la cual se encierra en sí misma y se automargina de cualquier narración que la cruce.

9 Los dos últimos puntos expresados en el párrafo anterior, terminarán por edificar una imagen cinematográfica-audiovisual de escasa densidad, que no es capaz, generalmente, de problematizar su relación con la naturaleza como motivo recurrente en sus imaginerías. Esto será tanto de forma directa, cuestionando los problemas entre imagen y referente material -es decir, cómo lo natural puede determinar las formas de lo audiovisual-, como de forma indirecta, haciendo visible la relación entre imagen y referentes estéticos, generando redes referenciales sobre las formas en que se ha proyectado a la naturaleza como motivo al interior del propio cine, pero también en las artes visuales, la literatura, etcétera. Es decir, padecer, confrontar, criticar o reelaborar cierta tradición, convención o imaginario simbólico sobre la naturaleza.

En este sentido, nos abocaremos a plantear una reflexión que pueda dar algunas pistas de esa memoria cinematográfica extraviada, de esas imágenes olvidadas entre censuras abiertas frente a ciertos tipos de cines $^{2}$, incendios constantes ${ }^{3}$ y nulas políticas de conservación en los primeros años y en muchos más que los siguieron ${ }^{4}$. Buscaremos algunas perspectivas que hagan visible la presencia del problema conceptual de la naturaleza desde los primeros esbozos del cine local, sobre todo cuando se tiene como norte el problema discursivo del concepto de nación que se plantea de forma expresa en los escritos sobre el cine primitivo chileno, los cuales tempranamente identifican la configuración de un cine chileno en la medida en que se ponga a trabajar en la construcción de una identidad nacional.

Proponemos el concepto de cine primitivo para referirnos a las primeras producciones cinematográficas locales por dos razones; la primera es que fue un concepto acuñado por el cineasta Pedro Sienna ${ }^{5}$, cuando pensaba en su rol en el cine mudo chileno: "Producción muda, producción sonora. Ya tenemos primitivos y renacentistas. Los primitivos ya cumplimos de sobra con lo que nos habíamos propuesto, esto es, echar los cimientos del futuro cine nacional" (SIENNA en SANTANA, 1957: p. 11), respondiendo de forma orgánica al propio desarrollo local, sin transformarse en un concepto absolutamente extrínseco. Pero, a su vez, consideramos que las imágenes de dicha época responden a lo que Nöel Burch denominó " Modo de Representación Primitivo " del cine, es decir, un protagonismo fundamental de la "frontalidad, distancia, carácter centrífugo, autarquía de los cuadros" (BURCH, 2006: p.92), lo cual se mantuvo con fuerza hasta los últimos filmes desarrollados por Pedro Sienna en que se dejan ver las primeras huellas de una desteatralización de la imagen cinematográfica ${ }^{6}$.

Esta condición inicial e inestable en las estrategias de significación del cine, se vuelve altamente significativa a la hora de pensar el problema que nos aboca, ya que en el cine de la época existe una brecha muy clara entre lo que las imágenes logran en sus operaciones visuales y aquello que se piensa de las mismas. Esta desincronización del discurso escrito y el de la imagen, esta no-correspondencia entre dos regímenes de significación, vuelve más evidente la operación discursiva de la idea de cine que antecede al propio cine chileno. Como lo plantea Jacques Rancière, "cine, al igual que pintura o literatura, es algo más que el nombre de un arte cuyos procedimientos pueden deducirse de la materia y del dispositivo técnico que lo caracterizan. Como ellos, es un nombre del arte, cuyo significado trasciende las fronteras de las artes" (RANCIÈRE, 2005: p.13), el cual "como idea del arte preexiste al cine como medio técnico y arte concreto" (RANCIÈRE, 2005: p. 15). 

(1915-1918), se publicó un extenso escrito a propósito del filme La agonía de Arauco (o el olvido de los muertos) [1917], de Gabriela von Bussenius -en el contexto de lo que podríamos llamar el primer boom del cine chileno ${ }^{8}$, en el cual se expresaba con contundencia la problemática entre naturaleza y nación: también un film de propaganda de las bellezas naturales de nuestro país. Por esto las escenas se desarrollan en los más variados puntos de nuestro territorio, principiando por Viña del Mar, el aristocrático balneario, hasta llegar a los últimos confines de nuestra frontera, en la zona de los lagos, bosques y mapuches. (Agosto de 1917: p. 3)

Año siguiente, encontraremos una serie de referencias a la naturaleza, en relación a diferentes filmes; no obstante, aparecen llamativas las consideraciones que hará Lucila Azagra, directora de La semana cinematográfica (1918-1921), sobre el filme Todo por la patria (1918), de Arturo Mario y María Padín. "Nos limitaremos, pues, a decir que el público no sólo ha encontrado esta pieza muy de su agrado, sino que la ha aplaudido con entusiasmo. Al ver pasar por la tela los paisajes de nuestros campos y al ver moverse en ella a los sencillos pobladores de nuestras aldeas" (AZAGRA, 23 de mayo de 1918: p.9-12). La misma rescatará unos meses después y a propósito del filme $L a$ avenida de las acacias (1918), de Arturo Mario, "llamaron también justamente la atención, además del buen desempeño de los artistas, los bonitos paisajes que figuran en la cinta y que dan idea de la belleza de algunos de nuestros campos, aldeas y ciudades" (AZAGRA, 5 de septiembre de 1918: p. 14).

\section{Todo por la patria (1918), de Arturo Mario y María Padín}

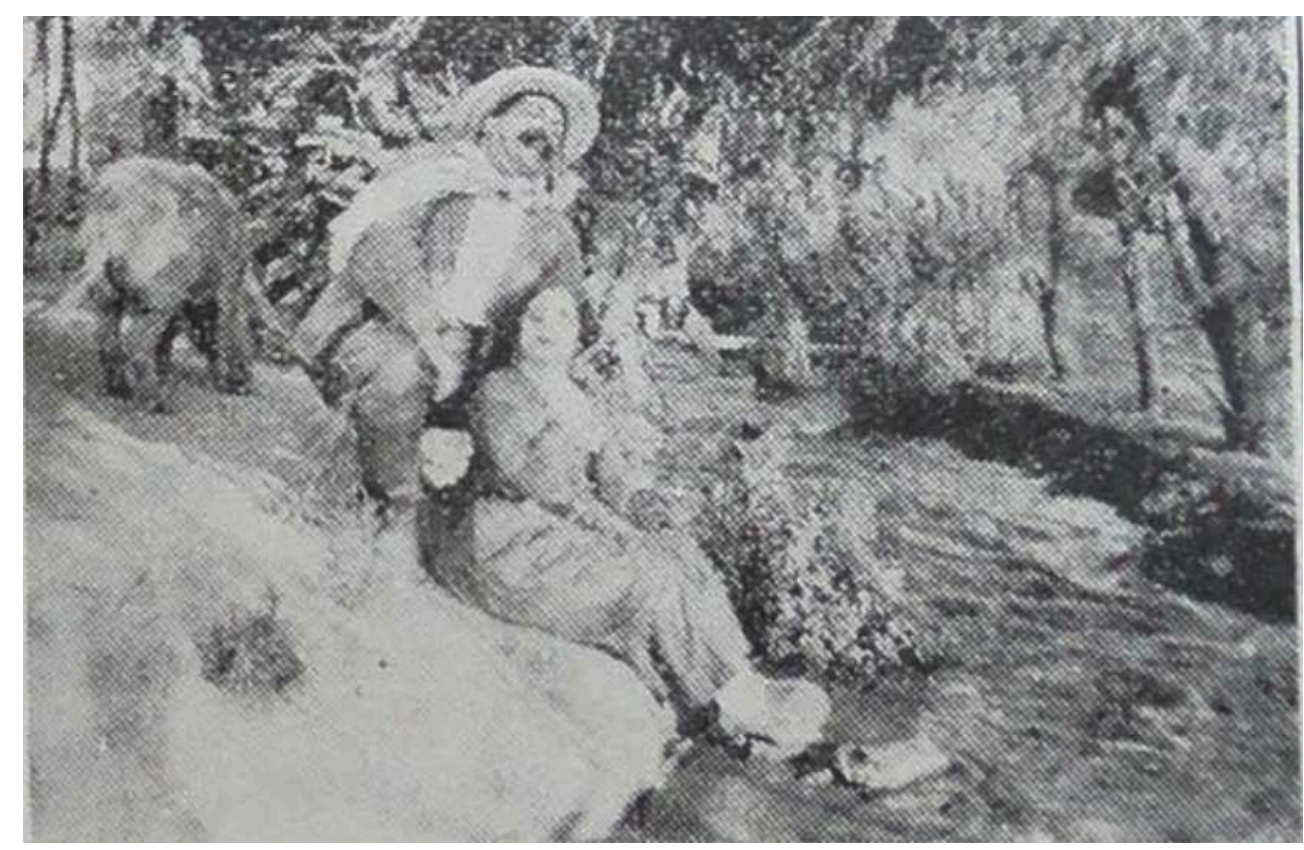

Revista La semana cinematográfica No 3

El mismo año en que Azagra rescata todas las escenas en que aparece la naturaleza territorial (esas " bellezas naturales de nuestro país »), encontramos un artículo 
publicado en la revista El Film (1918-1919), firmado por Manuel García Hernández, titulado "La naturaleza y la cinematografía", donde se despliega una relación orgánica entre el cine y la naturaleza. Comenzará plateando que "en la cinematografía ha llegado tanto a seducir el hábito de la más moderna mise en scène como las más desnuda visión de la naturaleza" (GARCÍA HERNÁNDEZ en BONGERS et al., 2011: p. 43), para continuar unas líneas más abajo: "[en] la exposición de Leonardo Da Vinci: " una cosa natural vista en un gran espejo ", está sintetizada toda la representación de la naturaleza en nuestro mundo sensible". Luego describirá la relación existente intrínseca entre naturaleza y cine en la cinematografía norteamericana, destacando que EE.UU. tiene "una rica tela en su naturaleza. En ella puede la cinematografía ensayar una obra de utilidad, de educación y de interés". Más adelante, describe la frondosidad de la naturaleza sudamericana y sus posibilidades pictóricas/expresivas. "La vida pintoresca americana no solo alcanza a la europea, sino que la supera, ora por sus costumbres típicas como por sus encantos donde la mano del hombre ha permanecido proscrita" (GARCÍA HERNÁNDEZ en BONGERS et al., 2011: p. 44). Termina por describir, nuevamente, tanto la gama multicolor y estridente como la calma y el silencio de los paisajes sudamericanos, concluyendo en el párrafo final:

En fin, creemos que la cinematografía debe extender sus miras al campo. El paisaje siempre permitirá dejar en descanso el folletín, ofreciendo en su tranquilo reposo, rincones de paz, de trabajo, a cuya sombra pequeñas comarcas viven grandes vidas de felicidad, bajo el cielo diáfano y frente al oro limpio del trigo que brilla al sol...

17 Esta intensidad que dotaría lo cinematográfico aparecerá también en el número 44 de la publicación Mundo Teatral (1918-1921), en un artículo en que se comentan las actualidades cinematográficas de 1920. Aquí se plantea, refiriéndose a la relación entre cine y teatro local, que este último "puede dar interesantes argumentos al futuro Cine Chileno, pues nuestras costumbres y modalidades, nuestros paisajes y ciudades impresionadas en el lienzo tomarán una vida nueva y poderosa, que irá más lejos y perdurará más que la vida de la representación, que desgraciadamente es por ahora bastante efímera" (en BONGERS et al., 2011: p. 222); unos párrafos más abajo sancionará, "la industria norte-americana solo pudo surgir, cuando un sabio nacionalismo inculcó que era deber el protegerla [...] cuando tenemos los medios de sentir y expresar nuestras bellezas y defectos que nos interesan muchos más que el sentir de otras razas y otros países" (en BONGERS et al., 2011: p. 223).

En la misma sintonía encontraremos un escrito impreso en el tercer número de la revista Arlequín (1922): "nuestro país es privilegiadamente pintoresco. Nos extasiamos mirando fjörds noruegos y nosotros tenemos más bellos en el sur. Tenemos nuestra cordillera, nuestro puerto de Constitución, nuestro campo, tenemos un clima envidiable, nuestro país nos abre los brazos y no queremos ir a él" (en BONGERS et al., 2011: p. 232). Por último, y sólo con afán de insistir en la fascinación paisajística de la época, el diario El Mercurio de Valparaíso, destacará las "melancólicas puestas de sol, claros amaneceres, bellos paisajes, jardines a la luz de la luna" (30 de diciembre de 1924), refiriéndose al ya citado Un grito en el mar de Pedro Sienna. 


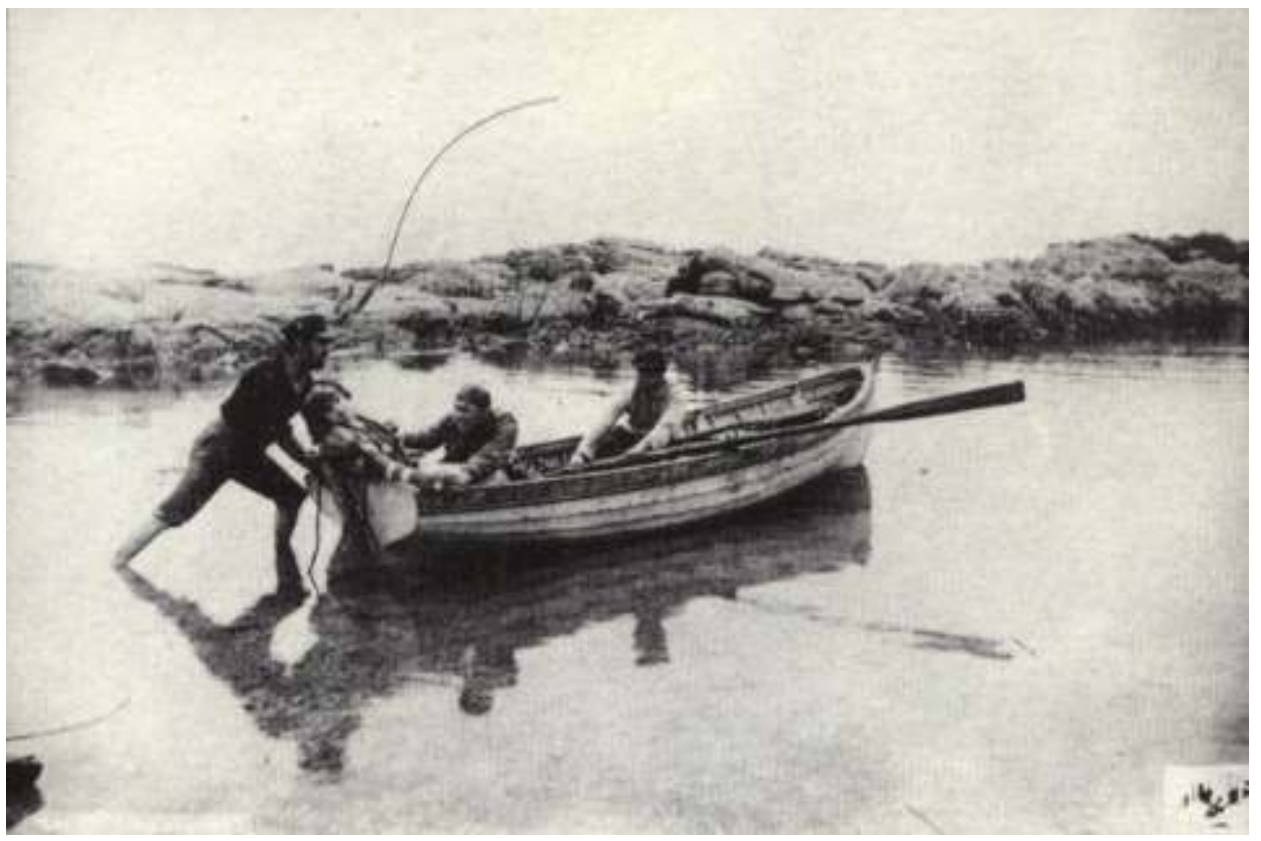

En Vega, Alicia (1979) Re-visión del cine chileno.

Santiago de Chile: Editorial Aconcagua

Desde una perspectiva diametralmente distinta, encontramos un artículo en 1921 firmado por Alberto Edwards en Pacífico Magazine (1913-1921), titulado "Los problemas del cine. Posibilidades de la cinematografía nacional". Éste no está preocupado de la particularidad visual de la naturaleza nacional como todos los extractos anteriores, sino, por el contrario, se concentra en como ésta puede estar al servicio de múltiples ficciones que desborden completamente al ámbito nacional y con ello constituir una industria cinematográfica nacional. Para esto comparará las condiciones culturales, geográficas, fenotípicas e idiosincrásicas de EE.UU., Europa y Chile.

Tras algunos párrafos en que marcará claramente la necesidad de pensar un cine local que se despoje de la historia y costumbres locales para triunfar en las pantallas de todo el mundo y hacer un análisis de las particularidades culturales que posibilitaron el auge de la industria cinematográfica estadounidense, se concentrará en la comparación geográfica entre California -cuna de Hollywood- y Chile. En este ejercicio planteará que el clima de California es el más análogo a Chile y ha sido parte fundamental de su éxito, ya que "el cine exige una atmósfera luminosa, muchos días de sol, un temperamento seco y poca lluvia. Estas condiciones no se encuentran en el Oriente de los Estados Unidos y menos todavía en la Europa Occidental. Chile las posee aun en mayor grado que California" (EDWARDS en BONGERS et al., 2011: p. 226). Luego de sancionar que "la naturaleza, el paisaje, es otro de los factores esenciales al éxito del biógrafo", analizará las características geográficas favorables existentes en Chile:

[...] las condiciones actuales del cine exigen una decoración más plástica, más propia para figurar o evocar vistas de los países templados, que son el centro de la civilización cosmopolita, en cuyas ideas, costumbres y problemas han de inspirarse casi la totalidad de las películas. En California y todavía más en Chile se puede sin trabajo encontrar decorados para una escena que se suponga desarrollarse en Inglaterra, en Francia, en Italia, en Rusia, en Liberia, mejor dicho, en cualquier parte del mundo. [...] Aquí, en muy pocas horas de marcha, se encuentran (a lo 
menos para la fotografía) paisajes ingleses, montañas suizas, campiñas italianas, bosques tropicales, desiertos árabes. (EDWARDS en BONGERS et al., 2011: p. 227) factor que afea al paisaje local, pero que lo favorece en relación al de otras latitudes: "los árboles y arbustos un tanto polvorientos de chile son reproducidos por la fotografía como el ojo ve a los de los otros países, llenos de luz, de sombras, de relieves". Uno de sus ejemplos será el secreto del paisaje europeo, el cual se sostiene en un leve contraste entre el verde oscuro del follaje y una tonalidad más clara de las praderas, que el material fotoquímico no logra expresar, transformándolo en una tonalidad uniforme. Pero en Chile las "praderas agotadas y amarillentas por los calores y la sequedad del estío, se destacan en la cámara fotográfica, como el ojo ve las risueñas y frescas praderas de los países húmedos. Allá la fotografía echa a perder al paisaje y aquí lo mejora". Para finalmente sancionar: "la naturaleza nos ha proporcionado gratuitamente un verdadero filtro acromático. De lo dicho se deduce que, en materia de factores naturales, los de Chile son inmejorables para la industria del cine" (EDWARDS en BONGERS et al., 2011: p. 228).

A la luz de las reflexiones que hemos citado, que habrá que reconocer corresponden a un amplio abanico de publicaciones -no todas ellas regulares y sistemáticas en sus reflexiones, pero que sintomatizan la relación entre naturaleza y cine local de forma evidente-, podremos plantear que hay algo por pensar en esta relación, que supera la mera disposición estética de un motivo (la naturaleza) frente a cualquier otro, pero que también supera con creces la mera simbolización de un territorio común que nos permita después hablar de lo nacional. Al interior de estas discusiones se articula una comprensión de lo cinematográfico, que apela a cierta especificidad, que desde ésta le posibilita desplegarse sobre la naturaleza y lo nacional.

Cuando García Hernández plantea al inicio de su escrito que el cine ha seducido no solo por la puesta en escena, sino también por las posibilidades que tiene de mostrar « las más desnuda visión de la naturaleza ", está planteándose una de las discusiones fundamentales del cine, que es su relación con la realidad, es decir, la capacidad que tiene de convocar aquello que está dado por fuera de la representación-el ejercicio estético del artista-. Esta discusión será en la que insistirá André Bazin a través del concepto de inconsciente fotográfico, para forzar, principalmente, al cine norteamericano a salir de su «espectacularización» cinematográfica9. La comprensión temprana que tiene la cinematografía local de las posibilidades expresivas de la realidad, es aquello que organiza tímidamente una discusión sobre la especificidad del cine.

En este sentido, la insistencia por el paisaje natural se vuelve significativa, ya que se comprende como un componente fundamental del desarrollo cinematográfico $\mathrm{y}$, a su vez, se vincula con otros elementos que irán apareciendo en el panorama local, como son: 1) El rescate de personajes comunes y corrientes -«los sencillos pobladores de nuestras aldeas» escribía Azagra en una de las citas anteriores-, o cuando en relación a Alma Chilena (1917), de Arturo Mario, se publica: "la nobleza de un roto humilde, tosco, ordinario, pero generoso y que llega a ser el único amigo de la desgracia" (CINE GACETA, octubre de 1917: p. 8). 2) La búsqueda de temáticas que sean propias de la vida del país; a propósito del filme ¿Por qué delinquió esa mujer? (1924), de Marcelo Derval, se 
dirá en el diario El Mercurio de Santiago: "Ahí no hay nada de esas cursilerías ramplonas de muchas películas importadas, ahí hay solo un pedazo de vida llevada con todo arte a la pantalla" (3 de octubre 1924). En el mismo diario se destacarán "las escenas de la vida del circo, pletóricas de emoción, de sencillez, de gracia y de verdad" (18 de mayo 1921), en referencia a Los payasos se van (1921), de Pedro Sienna. 3) El necesario rigor historiográfico de las producciones locales; a propósito de Todo por la patria se publicará:

Los anacronismos han sido cuidadosamente evitados y hasta los trenes históricos han sido facilitados galantemente por el señor Luis Vargas Salcedo, administrador de zona de los Ferrocarriles del Estado.La obra ha sido ajustada estrictamente a la verdad histórico. Se han salvado con exquisito tacto todos los escollos que pudiera herir susceptibilidad del pueblo peruano y es exaltado el heroísmo de los dos en lucha. (POPE, 1918: p.16)

Cuando la producción cinematográfica nacional se consolidó y fue abandonando el « Modo de Representación Primitivo ", se comenzó a destacar, también, las interpretaciones que se distanciaban del registro teatral. Un ejemplo de esto será el comentario de Pedro Sánchez en el diario La Nación sobre el personaje infantil, el Huacho pelao, en El húsar de la muerte (1925), de Pedro Sienna. "Me dicen que es un suplementero. Estamos entonces en presencia de un artista espontáneo. Imposible más naturalidad, más posesión de su papel, mayor sinceridad, más emoción" (SÁNCHEZ, 1925: s/n pp.). Esto también aparecerá en la reseña ya citada del filme Un grito en el mar de Sienna en el diario el Mercurio de Valparaíso, "Pedro Sienna, cuyo correcto trabajo sale de lo normal y se distingue por la conciencia y sensación de realidad que da a su papel" (19 de diciembre de 1924).

Todos estos elementos van edificando esa idea del cine chileno a la que hacíamos referencia al inicio del artículo, esa que lo proyecta más allá de sus propias fronteras como arte; es decir, que cuando nos enfrentamos a un filme local, esperamos encontrarnos con ciertas convenciones y pretensiones estéticas, que en última instancia comprenderán a la imagen cinematográfica como un espejo de la realidad. Apoyados en esta certidumbre se vuelve profundamente evidente porqué se puede creer que la imagen cinematográfica puede contener la identidad nacional, como, a su vez, provocar su más profunda crisis, ya que ésta puede alojar en su seno la violencia irreductible de la realidad. Todo esto se vuelve aún más interesante, ya que se está operando en el contexto de una discusión sobre aquello que haría específico al cine y que lo diferenciaría de las otras artes. Un ejemplo muy claro de esto, son las ventajas del cine frente al teatro, que se comprendía como su pariente más cercano. En la cita que hicimos del Mundo Teatral, se planteaba que el cine «perdurará más que la vida de la representación [del teatro] ». Pero, además, el cine posibilitaría acceder a « un pedazo de vida ", en palabras de los cronista de El Mercurio de Santiago. El cine sería un arte que a través de la reproductibilidad podrá dar acceso infinitas veces a ese presente que se pierde en el devenir del tiempo, pero también accede a la caducidad de la cotidianidad de la vida, que la representación teatral no podría tocar. De forma directa o indirecta se está ensayando una idea sobre el cine que lo vincula directamente con la realidad, que se verá reforzada en las posibilidades que éste tiene de recuperar el pasado. En este sentido, a propósito de El húsar de la muerte, se escribe en el diario La Nación que "sus escenas sencillas y nítidas deban esa impresión agradable de estar viviendo esa época de hazañas y glorias" (25 de noviembre 1925). 
Esta discusión se hará aún más evidente cuando Juan Emar, unos de los personajes más influyentes para la constitución de un ideario moderno del arte en $\mathrm{Chile}^{10}$, critique abiertamente el filme Golondrina (1924), de Nicanor de la Sotta, y con ello la escena cinematográfica local. Emar escribirá: "nuestro cine no ha hecho progreso alguno. La causa es clara; se parte de un principio falso, una literatura infantil, salpicada con dicharachos al gusto de la galería y máximas filosóficas-morales al gusto de los asistentes a platea" (EMAR, en BONGERS et al., 2011: p. 237), para luego continuar, "el cine en ellas es lento, sin variaciones y son los letreros los encargados de sostener el drama. Mientras el arte de la pantalla sea concebido de ese modo, nuestro cine quedará estacionario. El cine es un arte completo, que menos que ningún otro, necesita pedir apoyo a sus vecinos. Sus enemigos son el teatro y la literatura". Luego hará una descripción y defensa del lenguaje cinematográfico desarrollado en otros países, valorando el movimiento y el contraste rítmico de las imágenes del cine norteamericano, como así mismo el desarrollo fotográfico alemán y la fidelidad con los materiales del cine sueco y francés.

Dentro de esta discusión sobre cierta especificidad cinematográfica, el motivo de la naturaleza jugará un rol fundamental. El propio Emar destacará que uno de los poco valores a rescatar de Golondrina "son algunos hermosos paisajes»; en lo natural se encontraría una virginidad que devolvería a lo cinematográfico su dimensión más primigenia, cuando exponía en modestas vistas documentales escenas en las que no tenía ningún control. La naturaleza le devolvería esa génesis a través de un motivo que carece de intervención humana, transparente a cualquier subjetividad que determine su imagen. Así se opera un doble movimiento que constituye la condición de posibilidad para la comprensión identitaria de la naturaleza; por un lado, le devuelve al cine su origen indeterminado en la carencia de puesta en escena, y por el otro, hace ingresar en su imagen todo aquello que no ha sido contaminado por el propio andamiaje cultural. La naturaleza, en su condición de paisaje, dotaría a la imagen de su condición más prístina de espejo.

El último aspecto relevante será que a pesar de esto último, en la escena local no se aprecia la dimensión documental de la imagen; es decir, de aquello que se habla y escribe en las revistas y periódicos es de las ficciones cinematográficas y no de las piezas o vistas documentales. Por ejemplo, no existe ningún comentario más allá de anotaciones marginales del trabajo de «actualidades cinematográficas»-proto documentales periodísticos muy comunes y populares en la época- llevado a cabo por Salvador Giambiastiani. Entre muchos otros filmes, hará el Recuerdo del mineral "El Teniente" (1919) ${ }^{11}$, que en la actualidad se considera el primer antecedente para hablar del documental chileno y uno de los pocos filmes que existen de la época. Habría que plantear desde aquí dos posibilidades a continuar trabajando. 1) El cine emerge en toda su gravedad cuando éste toma las formas de la ficción. 2) La naturaleza se vuelve profundamente más significativa cuando instala al interior de la puesta en escena la irreductible indeterminación de su presencia.

$$
* * *
$$

Establecer la relación teórico-estética entre naturaleza y cine en las décadas del diez y veinte se vuelve un ejercicio complejo, pues la mayoría de los filmes están desaparecidos y los pocos que quedan se transforman en meras excepcionalidades. Es 
difícil poder trabajar con esta época aún cuando generemos un trabajo arqueológico, donde al análisis se incorporen los fotogramas que aún perduran de esos filmes, las fotografías de los rodajes, las piezas gráficas y reseñas o reflexiones sobre los filmes. Esta estrategia funciona ahí cuando la mirada se concentra y acota en un territorio bastante específico o en ejercicios más bien generales de corte historiográficos. El extenso territorio entre ambos puntos es un descampado de difícil fertilidad o reconstrucción, en el cual justamente se articula el problema de este articulo. Será por esto que haremos dos pequeñas exégesis, las cuales pueden aparecer fragmentarias y de escaso alcance, pero consideramos permitirán dar algunas líneas a seguir.

En los diferentes textos citados en este artículo podremos encontrar dos perspectivas de la relación entre nación y naturaleza al interior del cine chileno primitivo, pero que parten de un punto común: la comprensión de la naturaleza como el motivo que le devolvería a la imagen cinematográfica su condición más prístina de espejo. Desde ésta se proyectará la relación entre naturaleza y nación como una forma efectiva de propaganda del país; pero pensándola principalmente hacia el interior del mismo, ahí aparecen frases como: « Haciendo obra patriótica, la «Chile Film» quiso que «La agonía de Arauco» fuera también un film de propaganda de las bellezas naturales de nuestro país » o cuando se plantea que el público « ha aplaudido con entusiasmo. Al ver pasar por la tela los paisajes de nuestros campos » en relación a Todo por lo patria.

En este sentido, del cine se esperaba que vehiculizara a los centros urbanos una imagen país, donde la naturaleza es la certidumbre de su existencia efectiva, incorporando una serie de territorios ausentes del imaginario simbólico en una discursividad de lo colectivo. La imagen cinematográfica se concibe como un espacio de reconocimiento, pero fundamentalmente de revelación de lo ignorado o lo oculto, lo cual constituiría a todos los habitantes de la nación. En ello consiste su labor propagandística, ya que trae las pistas de lo indimensionable y de lo inenarrable al presente, para irrumpir en el imaginario marcándolo y transformándolo, eso que en el Mundo Teatral se expresaba en los siguientes términos: el cine nos da "los medios de sentir y expresar nuestras bellezas y defectos que nos interesan ».

Esto se sostendría en las potencialidades estéticas inherentes de la naturaleza de contener aquello que se cifraría obtuso a la comprensión humana, como lo planteaba García Hernández: esos «encantos donde la mano del hombre ha permanecido proscrita», pero que determina trascendentalmente su identidad. El cine nos permitiría acceder a una paz ausente de la vida cultural, un espacio del reposo «bajo el cielo diáfano y frente al oro limpio del trigo que brilla al sol ", que se demuestra profundamente democrático, ya que no exigiría una herencia cultural sino la capacidad de dejarse afectar por la magnitud de la naturaleza. No obstante, este llamado estético de la naturaleza pareciese no ser escuchado; en el escrito de Arlequín destacábamos «nuestro país nos abre los brazos y no queremos ir a él», para fascinarnos por paisajes extranjeros, es por esto que nace la necesidad propagandística de la naturaleza como motivo representacional de lo nacional.

No obstante, ésta no será la única comprensión de la relación entre naturaleza y nación; otra manera de entenderla es cuando la primera se comprende como materia prima para el desarrollo de la nación -como planteaba Edwards-, la cual nos permite nuestra segunda exégesis. En su largo artículo queda claro que la naturaleza local debe abandonar su particularidad, invisibilizarse y ausentarse, para desde ahí transformarse en un valor al servicio de la industria cultural del cine nacional. Ésta -como también lo 
que podríamos llamar costumbres chilenas-no tiene ningún valor en su contemporaneidad si no está al servicio de una modernidad cosmopolita, es decir, integrada a un movimiento general de valores trascendentales y colectivos de la humanidad, que estarían cristalizados por los ideales occidentales europeos.

Todo aquello autóctono es un ruido que debiera ser extirpado de las producciones locales, para generar una industria equiparable a la norteamericana. Lo que queda suficientemente expresado cuando Edwards plantea que en Chile no existe mucha dificultad de encontrar «paisajes ingleses, montañas suizas, campiñas italianas, bosques tropicales, desiertos árabes». El paisaje local -y ese será su valor constitutivo para lo nacional-, es una reunión variopinta del mundo, un crisol estético en que emerge la absoluta proliferación visual del mismo. Lo nacional, pensado así, es justamente la renuncia a cualquier particularidad que nos saque del ritmo cultural del presente.

Vale la pena enfatizar dos elementos en el razonamiento de Edwards: primero, su sincronización con los discursos actuales frente a la globalización y a sus procesos culturales, lo que podríamos ver reflejado en el filme Quantum of solace (2008) de Marc Forster, uno de los filmes de la saga del personaje inglés James Bond, donde se ocupan los paisajes del norte de Chile para ubicar una narración en Perú. El segundo es que sus ideas reclaman una profunda reflexión estética, marcando aquellos elementos que particularizarían al cine; pero aún más, al remarcar que la potencia de la naturaleza local se encontraría en que es profundamente cinematográfica, ésta «nos ha proporcionado gratuitamente un verdadero filtro acromático», escribía Edwards. Éste establece una estrecha relación entre estética e industria, donde Chile debería ponerse al servicio de la industria cultural, no porque en ella exista algo relevante para el desarrollo cultural, sino porque existen las materias primas necesarias para el desarrollo de esta industria. El giro propuesto por Edwards es radical; en éste encontramos una reflexión que intenta resolver -sin hacerlo premeditadamente- la querella entre arte y técnica que marcará todo el siglo XX occidental, desde las ideas Martin Heiddeger y Walter Benjamin, hasta aquellas de Paul Virilio y José Luis Brea.

Esta comprensión industrial de los valores estéticos inherentes de lo natural, que terminan por dimensionarla como mera materia prima, se ve simbolizada en el documental Recuerdos del mineral "El Teniente" de Giambastiani, el cual, según Alicia Vega, "con gran sencillez, informa [los] aspectos de la vida del mineral registrando las condiciones de trabajo, las diferencias sociales y miserias de un centro de producción" (VEGA, 1979: p. 227), a través de:

[...] una selección de planos que aborda en pequeñas unidades temáticas el mineral desde el punto de vista de los trabajos que allí se realizan: habitantes y edificios se Sewell; las viviendas; los ejecutivos y el trabajo en la oficina; trabajos en la red ferroviaria; la construcción de un tranque; la central hidroeléctrica; estación de Rancagua; las fiestas de fin de año. (VEGA, 1979: p. 227-228) 


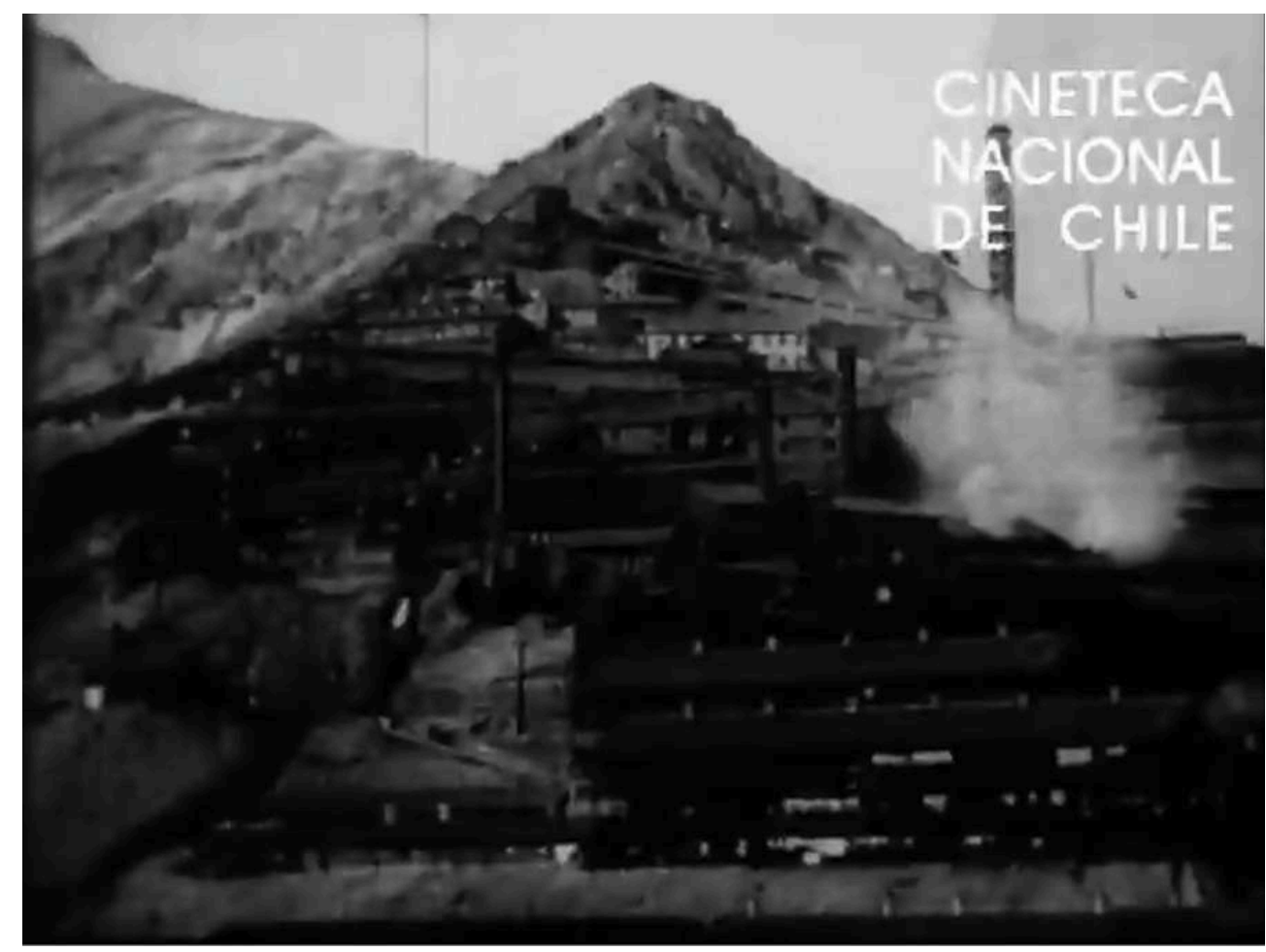

Cineteca Nacional de Chile

El filme inicialmente pareciese colocar a la naturaleza como telón de fondo para una serie de actividades humanas; no obstante la densidad simbólica de la naturaleza es mucho mayor, estableciendo una relación simbiótica entre técnica y naturaleza, ya que las maquinarias de explotación mineral han transformado la topografía y características del lugar; pero al mismo tiempo, la naturaleza determina las formas en que se proyecta la construcción de las edificaciones. Esto que tiene tintes de obviedad, nos presenta un estado de la técnica que aún necesita de la naturaleza para desplegarse, teniendo que negociar sus formas con las de la naturaleza. La actualidad de lo técnico dista mucho de esta relación conflictiva; éste a través de la digitalización no solo ha renunciado a la espacialidad natural, sino que ha clausurado en la virtualidad cualquier irrupción de la misma en el presente.

Ese estado de impureza de la técnica es el mismo que habita el cine de la época. Éste aún necesita de su referente para construir su imagen, pero más aún, necesita la certidumbre de la naturaleza para dotarlo de su mayor potencia realista. En la idea de que si el cine puede contener la visualidad irreductible de lo natural, éste puede apelar a una relación existencial con la realidad, por sobre cualquier convención representacional. No obstante ello, el filme de Giambastiani está inundado de la densidad representacional de la imagen cinematográfica, que se devela cuando los trabajadores y habitantes del mineral de Sewell posan y miran fijamente a la cámara, haciendo evidente la artificialidad del dispositivo de representación. 
Recuerdos del mineral "El Teniente" (1919), de Salvador Giambastiani

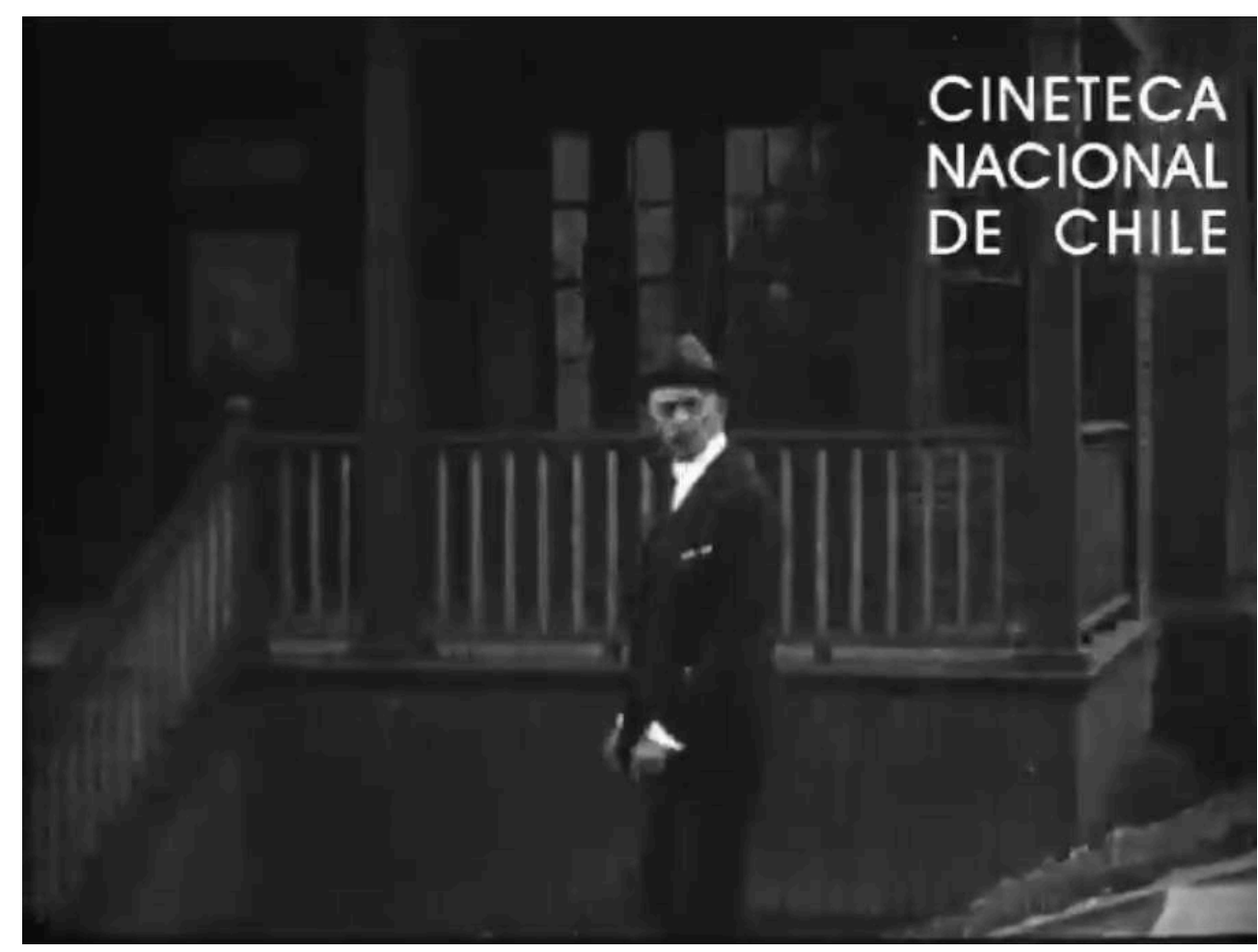

Cineteca Nacional de Chile

Así, la naturaleza no le exige a lo cinematográfico generar convenciones estéticas, como por ejemplo que las personas no miren a cámara para hacer invisible el dispositivo representacional, asegurándole la transparencia necesaria para contener el tiempo del presente y cargar con la temporalidad de la modernidad y los sueños de las masas. Será por esto mismo que, generalmente, la racionalidad técnica-cristalizada en las maquinarias y lógicas de explotación de la naturaleza-al interior del filme es naturalizada a través de paisajes y tomas generales, donde se funde con lo natural en una misma materialidad, indiferenciable. Lo técnico se presenta como un estado natural, absolutamente trascendente a lo humano, donde éste transita y vive pero sin poder afectar su devenir.

41 Para finalizar, no deja de llamar la atención que tanto en las comprensiones de la naturaleza que potencian su valor simbólico como en las otras que privilegian su valor industrial, persiste una idea similar de la naturaleza, es decir, ésta es portadora de una indeterminación trascendente a la temporalidad cultural. La primera convoca a la naturaleza en su dimensión de valor identitario, mientras la segunda le extrae para dotar a lo técnico de las formas de lo natural. En este sentido, lo que está en juego en esos textos que problematizan al cine local primitivo, es una forma de comprensión de la modernización cultural chilena, donde la naturaleza-como motivo representacional-, es concebida como un territorio de disputa y experimentación de discursos que desbordan por mucho al propio cine " como medio técnico y arte concreto ». 


\section{BIBLIOGRAFÍA}

AZAGRA, Lucila (1918) “Todo por la Patria”, en La semana cinematográfica № 4, 30 de mayo, Santiago-Chile. pp. 9-12.

AZAGRA, Lucila (1918) “La avenida de las acacias”, en La semana cinematográfica № 18, 5 de septiembre, Santiago-Chile. pp. 13-14.

BONGERS, Wolfang et al. (eds.) [2011] Archivos i letrados. Escritos sobre cine en Chile 1908-1940. Santiago de Chile: Editorial cuarto propio.

BURCH, Noël (2006) El tragaluz del infinito. Madrid: Ediciones Cátedra.

Enciclopedia del cine chileno, Cine Chile. (2009-2012). www.cinechile.cl. Santiago de Chile.

JARA, Isabel (2011) "Politizar el paisaje, ilustrar la patria: nacionalismo, dictadura chilena y proyecto editorial”. Aisthesis № 50 , Santiago de Chile. pp. 230-252.

GODOY QUEZADA, Mario (1967) “El mar en el cine chileno”. Revista en Viaje, Diciembre, Santiago de Chile. pp. 27-28.

MATURANA, Felipe A. (2006) "El documental fueguino chileno en el siglo XXI: una mirada desde la antropología visual”. Magallania V. 34, № 1, Punta Arenas. Disponible en:

MOUESCA, Jacqueline (1988) Plano secuencia de la memoria de Chile: veinticinco años de cine chileno (1960-1985). Madrid: Ediciones del Litoral.

PEIRANO, María Paz (2006) "Nosotros, los otros". Boletín del Museo Chileno de Arte Precolombino V. 11, № 1, Santiago de Chile. pp. 55-66.

PINTO VEAS, Iván (2009) “Alicia en el país. Transparencias en la imagen”. LaFuga.cl, Santiago de Chile. Disponible en:

POPE, Augusto. (1918) « Todo por la patria », en Cine Gaceta № 11 (segunda época), 2ª quincena de febrero, Valparaíso-Chile. p. 16.

RANCIERE, Jacques (2005) La fábula cinematográfica. Barcelona: Ediciones Paidós Ibérica.

RAMÍREZ, Christián (2008) "Impenetrable Naturaleza: El paisaje, el nuevo protagonista del cine chileno". Capital.cl, Santiago de Chile. Disponible en:

SÁNCHEZ, Pedro (1925) “El húsar de la muerte”, en diario La Nación, 27 de noviembre 1925, Santiago-Chile.

SANTA CRUZ, José (2010) “Arqueología visual, el caso de los filmes olvidados de Pedro Sienna”. Revista Chilena de Antropología Visual № 16, Santiago de Chile. pp- 59-77

SANTANA, Alberto (1957) Grandezas y miserias del cine chileno. Santiago: Editorial Misión.

Sin Autor (1917) “La agonía de Arauco”, en Cine Gaceta № 1 (segunda época), 2 quincena de agosto, Valparaíso-Chile. pp. 3-4.

Sin Autor (1917) “Alma Chilena”, en Cine Gaceta № 4 (segunda época), 2ª quincena de octubre de 1917, Valparaíso-Chile. pp. 7-8.

Sin Autor (1921) “Sección Cinematógrafos”, en El Mercurio, 18 de mayo, Santiago-Chile.

Sin Autor (1924) “¿Por qué delinquió esa mujer?”, en El Mercurio, 3 de octubre, Santiago-Chile. 
Sin Autor (1924) "Un grito en el mar”, en El Mercurio de Valparaíso, 30 de diciembre, ValparaísoChile.

STANGE, Hans y SALINAS, Claudio (2008). "La incipiente literatura sobre cine chileno. Obra en construcción”. LaFuga.cl, Santiago de Chile. Disponible en

SUBERCASEAUX, Bernardo (2006) "La cultura en los gobiernos de la concertación”. Universum V. 21, № 1, Talca. Disponible en:

VEGA, Alicia (1979) Re-visión del cine chileno. Santiago de Chile: Editorial Aconcagua.

\section{NOTAS}

1. Mario Godoy Quezada, fue un periodista chileno que publicó en 1966, Historia del cine chileno, en el cual se reúne una serie de eventos ordenados cronológicamente sobre la historia del cine chileno. Pero como advierten Hans Stange y Claudio Salinas, este texto inaugura un "énfasis en la narración de los acontecimientos del cine nacional. Hablamos de narración y no de historia pues estos libros no poseen un afán disciplinario, un especial manejo de datos ni la presentación de hipótesis" (STANGE y SALINAS, 2008: s/n pp.). Así mismo, habría que plantear que al texto de Godoy Quezada le antecede una recopilación histórica hecha por el cineasta nacido en Iquique, Alberto Santana, titulado Grandezas y miserias del cine chileno (1957), el cual ha citado en este artículo. No obstante, éste se muestra más como una reunión de memorias personales, que con algún rigor historiográfico.

2. Solo con afán ilustrativo sobre este punto citamos el punto 8 del Manifiesto de los cineastas de la Unidad Popular (1970): "8. Que sostenemos que las formas de producción tradicionales son un muro de contención para los jóvenes cineastas y en definitiva implican una clara dependencia cultural, ya que dichas técnicas provienen de estéticas extrañas a la idiosincrasia de nuestros pueblos" (en MOUESCA, 1988: p. 71) Este texto marca una brecha entre dos mundos de cineastas muy distintos, aquellos que se hicieron al interior de los estudios y esos que emergieron en las escuelas o universidades, pero también implicará un rechazo a esas imágenes e historias determinadas por esas condiciones materiales de desarrollo artístico.

3. Quizás el primer gran incendio para la historia del cine chileno será el ocurrido a los estudios Hans Frey de Valparaíso en 1919, la cual fue la casa productora del filme Todo por la patria (1918), de Arturo Mario, que destaca por ser el primer filme sobre la Guerra del Pacífico (1879-1883), entre Chile, Perú y Bolivia. En el siniestro se perdieron todos los negativos y copias del filme, a excepción de una que quedó en manos Luis Retana (autor de la novela que se adaptó en el filme), el cual no tenía derecho de exhibirla en Chile. Actualmente no existen rastros de dicha copia.

4. El problema de la conservación no fue extraño para la primitiva escena cinematográfica chilena, ya en 1915 se publicó en el segundo número de la revista Chile cinematográfico, un artículo titulado "Archivo cinematográfico", en que se abogaba por una política de conservación de las imágenes cinematográficas chilenas. "En el Quay d'Orsay en París se guardaron los films de todas las visitas y recepciones oficiales, a partir de la visita del presidente Mr. Faure a Rusia. En Chile no sabemos que se haya pensado en nada de esto" (15 de julio 1915).

5. Pedro Sienna (1893-1971), su nombre real era Pedro Pérez Cordero, fue poeta, actor, dramaturgo, cineasta, entre otros, sus títulos cinematográficos más importantes son Un grito en el mar (1924) y El húsar de la muerte (1925), en la actualidad y en su época fue considerado el cineastas más importante del cine mudo.

6. La desteatralización de la imagen en el dispositivo representacional del cine de Pedro Sienna lo trabajamos en un artículo anterior. Ver Santa Cruz, José (2010) “Arqueología visual, el caso de los 
filmes olvidados de Pedro Sienna". Revista Chilena de Antropología Visual № 16, Santiago de Chile. pp- 59-77

7. La primera época de Cine Gaceta fue entre 1915-1916 y se publicaba en Santiago de Chile, en cambio la segunda época, la cual duró entre 1917-1918, se publicó en Valparaíso.

8. Vale la pena señalar que en el primer número de la revista que referimos se encontrarán tres críticas a largometrajes de ficción, al ya nombrado de Gabriela von Bussenius, se encontraba Alma chilena (1917), de Arturo Mario, y El hombre de acero (1917), de Pedro Sienna, Rafael Frontaura, Jorge Délano y Nemesio Martínez.

9. El concepto de «espectacularización» fue acuñado por Guy Debord a propósito de las formas en que el sistema capitalista se instala en las esferas cotidianas a través de la cultura como forma de dominación y reproducción ideológica. Uno de los elementos fundamentales para espectacularización cultural es el divorcio de la imagen con el mundo, cuando detrás de ésta no existe sino otras imágenes. En este sentido, el sistema de producción por géneros en el cine de Hollywood -principalmente hasta la década de los sesenta- encontraría su energía vital en la renuncia del cine a cualquier anterioridad que no sea otra imagen.

10. Juan Emar (Álvaro Yáñez Bianchi) durante 1923 y 1927 fue columnista y crítico de arte del diario La Nación-de propiedad de su padre-. En este espacio ensayo y reflexionó sobre la condición moderna del arte al alero de las ideas de movimientos pictóricos como el fauvismo, el cubismo, el expresionismo, entre otros. Transformándose rápidamente en un referente para la escena pictórica chilena, que intentaba alejarse del criollismo y academismo pictórico, en los hombros del Grupo Montparnasse (1923-1930), en los cuales participaban los pintores Luis Vargas Rosas, Henriette Petit, Julio Ortiz de Zárate y José Perotti, entre otros.

11. La versión actual de solo 11 minutos, que se encuentra en la Cinemateca Nacional de Chile, fue reeditada en 1955 por Patricio Kaulen y Andrés Martorell, los cuales encontraron una copia en las antiguas bodegas de la Braden Copper Company en Rancagua, Chile. Esta copia no cuenta con la totalidad de los 12 rollos originales ni tampoco de los títulos explicativos de la versión original.

\section{RESÚMENES}

La naturaleza es un motivo representacional que ha cruzado la producción cinematográfica chilena desde su inicio; ésta no sólo ha figurado como un decorado sino que se ha pensado como parte fundamental de la construcción simbólica de la identidad nacional. No obstante, la relación entre cine y naturaleza no sólo es simbólica, sino que también está cruzada por la construcción de una idea del cine chileno y una comprensión sobre lo cinematográfico, que son la condición de posibilidad para la dimensión simbólica de la naturaleza. Esto lo encontraremos desde temprana data en los escritos sobre los primeros filmes chilenos y será analizando dichas líneas e ideas donde se visibilizará lo que está en juego cuando el cine chileno imagina a la naturaleza.

La nature est un motif de représentation qui a intéressé très tôt la production cinématographique chilienne depuis ses débuts. Elle n'est pas seulement un décor: elle a été pensée comme partie fondamentale de la construction symbolique de l'identité nationale. Cependant, la relation entre le cinéma et la nature n'est pas seulement symbolique, elle est également traversée par la construction d'une idée sur l'identité du cinéma chilien, ainsi que par une compréhension spécifique sur ce qui est de l'ordre cinématographique, ces deux éléments 
étant des conditions pour affirmer la dimension symbolique de la nature. On retrouve ceci dans les textes sur les premiers films chiliens et c'est en analysant ces écrits et ces idées que l'on pourra visualiser ce qui est en jeu quand le cinéma chilien imagine la nature.

\section{ÍNDICE}

Palabras claves: cine chileno, escritos de cine, cine mudo, naturaleza, nación Mots-clés: cinéma chilien, cinéma écrit, cinéma muet, nature, nation

\section{AUTOR}

JOSÉ M. SANTA CRUZ G.

Licenciado en Cine Universidad ARCIS (Chile), Magíster Historia y Teoría del Arte Universidad de Chile. Doctorado en Historia del Arte Universidad de Barcelona josesantacruzgrau[at]gmail.com 